\title{
Floristic, Ecologic And Pedologic Characterization of Semi-Natural Hay Meadows From Rodna Mountains
}

\author{
Adrian GLIGA ${ }^{1}$, Ioan ROTAR ${ }^{1 *}$, Mihai BUTA ${ }^{2}$, Florin PĂCURAR ${ }^{1}$, Agnes BALAZSI ${ }^{1}$ \\ Faculty of Agriculture, UASMV Cluj-Napoca, Calea Mănăștur 3-5, Cluj-Napoca, Romania; *Correspond- \\ ing author, e-mail: rotarioan52@yahoo.fr
}

Bulletin USAMV series Agriculture 71(2)/2014

Print ISSN 1843-5246; Electronic ISSN 1843-5386

DOI 10.15835/buasvmcn-agr: 10837

\begin{abstract}
In this study we analyzed in terms of flora, ecological and pedological aspects three semi-natural hay meadows in Rodna Mountains. They are located in the north east of Bistrita-Nasaud county in the Valea Mare village area. The altitudes at which the meadows are located vary between 749 and 1292.5 meters. To determine the floristic compozition we used the Braun-Blanquet method with intermediate values and the ecological requirements of plants was performed using the Ellenberg vegetation indices. Pedological characterization has been described as a result of observed excavated sections and physico-chemical soil analysis performed in a specialized laboratory. In this study we determined two grassland types and three soil types. Environmental requirements of the plants were similar in the three studied locations.
\end{abstract}

Keywords: ecological characterization, floristic composition, pedologic characterization, Rodna mountains, semi-natural hay meadow.

\section{INTRODUCTION}

Semi-natural hay meadows, defined as unfertilized grasslands formed as a consequence of the land use, but largely populated by species of wild flora are among the ecosystems with the highest biodiversity in Europe (Veen et al., 2009).

Compared to other community types European grasslands have a rich flora and they may develop a very high small-scale species density (Pärtel et al., 1996). For example, the highest vascular plant species numbers are found at the tiny scale of a few square centimetres to one square meter in temperate grasslands. (Kull and Zobel, 1991).

IntheRodnaMountainsthereisadifferentiation of vegetal cover on altitude, closely related to climatic and edaphic factors (Doniță, 1985). These formations crop well physiognomic individualized characterizes a certain mountainous area and are scattered elevation in the form of "strips" of 300-500 m wide, forming vegetation floors and subfloors (Pignatti, 1980).

\section{MATERIALS AND METHODS}

Studies were conducted near the village of Valea Mare situated in the NE part of BistritaNăsăud county.
Three locations were selected in order to study their flora and soil, all of which are located at different altitudes. Their local names are: Arin, Dealul Negru and Fața Dâmbului (Figure 1).

To determine the floristic composition and the medium abundance-dominance of these haymeadows we used the Braun-Blanquet applied to an area of $25 \mathrm{~m}^{2}$ per survey using species lists compiled for this study. To assess the ecological requirements of the plants we used the Ellenberg vegetation indices (H. Ellenberg, 1988).

Soil types were evaluated based on excavated profiles, fallowed by a complex characterized after the laboratory analyzes.

\section{RESULTS AND DISCUSSION}

Following the floristic studies,we have identified two grassland types.

The first grassland type is characterized as Agrostis capillaris - Festuca rubra (A. capillaris F. rubra) which is part of Agrostis capillaris - Festuca rubra series, specific for the nemoral floor, beech forest undergrowth and mixed beech and resinous (TTUCRA et al., 1987). In our case, the A capillaris F. rubra type described in boreal floor at altitudes between 749 and $925 \mathrm{~m}$. This was encountered 


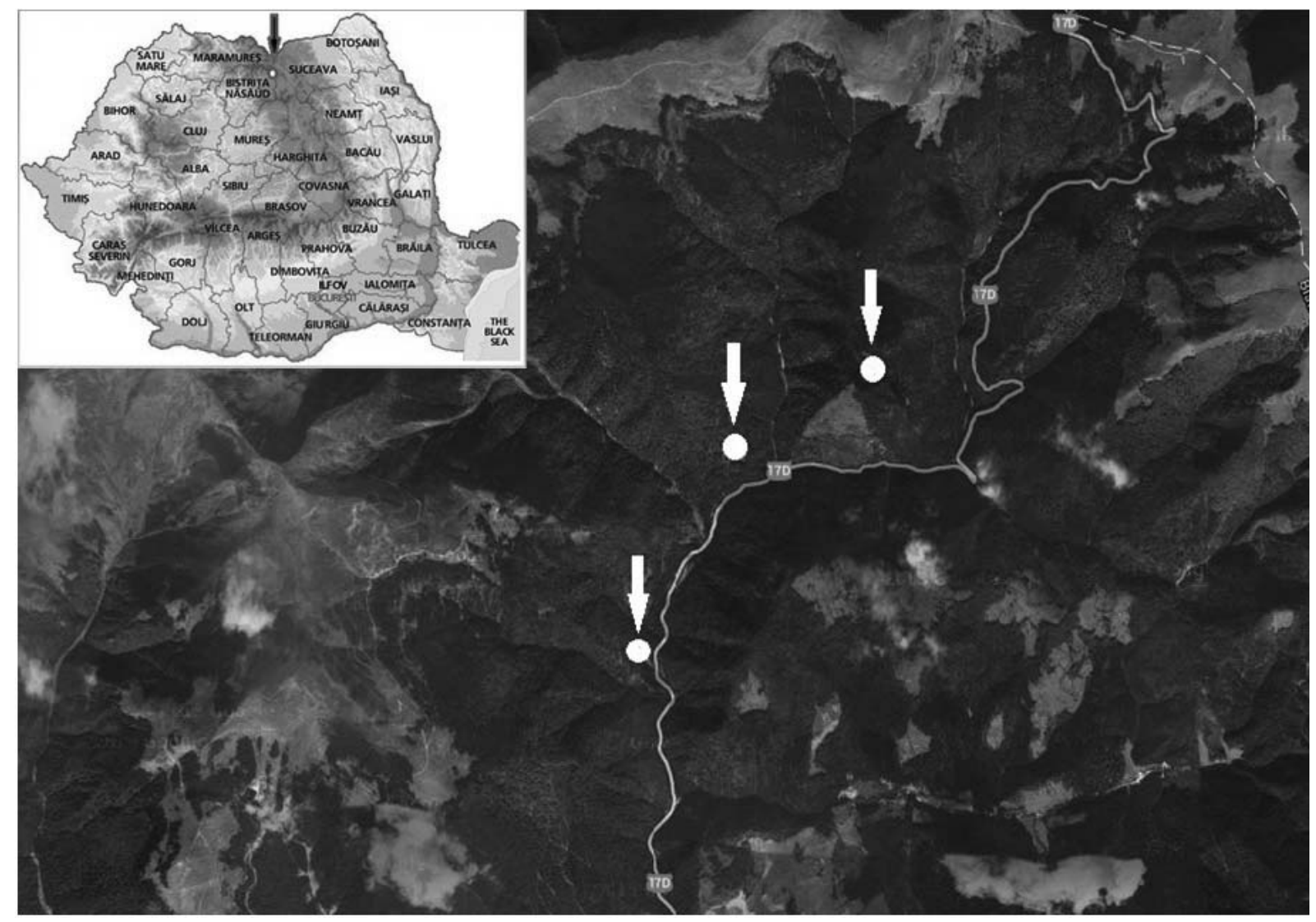

Fig.1. Research points location

in the locations named Arin and Dealul Negru, representing $66 \%$ of the studied grasslands, with southern exposition and general herbaceous vegetation coverage of average $109.5 \%$.

Poaceae family makes its presence felt in the grassy carpet with average participation of $42.65 \%$. Of Poaceae species that has the highest MAD is A. capillaris, with $24.5 \%$, with the most frequent coverage of $27.5 \%$, followed by Festuca rubra with a MAD of $16 \%$ and the most frequent value of the coverage was $17.5 \%$.

The medium participation of Cyperaceae and Juncaceae families for this type of grassland is very low $(1.1 \%)$. It meets one indicators species, namely Carex pallescens, the other species are just random.

Fabaceae family participates in the floristic composition on average by $28.8 \%$, reaching a maximum of $40.5 \%$. Among the species of Fabaceae the best participation has Trifolium repens $(13.75 \%)$, followed by Trifolium pratense (10.63\%), other species having a lower MAD.

Plants from other botanical families (ABF) are present in the A. capillaris - F rubra phytocoenosis type on average by $36.87 \%$, with a minimum of $17.3 \%$ and a maximum of $51 \%$. Some species in this group have a significant MAD, such as Alchemilla vulgaris with $14.05 \%$, Veronica chamaedrys $7.5 \%$ followed by Leontodon hispidum with $1.4 \%$. the other species have a lower participation of $0.5 \%$.

Festuca rubra - Agrostis capillaris (F. rubra - A. capillaris) phytocoenosis is present in the Fața Dâmbului station. Typological classification of this phytocenosis is quite difficult because the typology after ȚUCRA et al. (1987) does not mentiones it as a type or subtype. We can say that this type of phytocoenosis may be a shift from the Festuca rubra type to Agrostis capillaris type or vice versa. This grassland type is found at an altitude of between 1230 - $1292.5 \mathrm{~m}$.

Poaceae family participates in the grassy carpet with an average of $32.45 \%$ with a minimum of $24 \%$ and a maximum of $36.5 \%$. Of Poaceae species with the largest MAD is Festuca rubra with 16.25\%, followed by Agrostis capillaris with 15\%.

Cyperaceae and Juncaceae families have a high participation, averaging $18.3 \%$, reaching a 
maximum of $27.5 \%$ and a minimum of $11.25 \%$. Luzula campestris, has the largest MAD of $17 \%$.

The species of the Fabaceae family are present with an average of $15.4 \%$, with a minimum of $10.5 \%$ and maximum $19 \%$. The greatest participation is represented by Trifolium repens with a MAD of $6.6 \%$, followed by Trifolium pratense with $4.45 \%$ and Lotus corniculatus with a $4.3 \%$.

Plants from other botanical families (ABF) are part of the floristic composition of the F rubra - A. capillaris type with an average coverage of $30.5 \%$, with a maximum of $45.55 \%$ and a minimum of $14 \%$. The ABF plant species that have a important MAD are: Alchemilla vulgaris 7.7\%, Fragaria vesca 9.8\% and Trolius europeus 6.2\%. Other species have a more modest MAD up to $2 \%$.

Ecological requirements of plants determined on these research stations are presented as follows:
Plant communities from Arin station include 26 heliophytes species seven meso-heliophyte and two euryecious.

Regarding the temperature 27 species are eurytherm and seven microtherm.

As response to soil moisture 20 species are mesoxerophiles, 12 euryecious, and five mesophytes.

Compared to soil acidity sensitivity 21 species are euryacidophilous, six neutrophilous, four lightly acidophilous, and five moderate acidophilous.

The grassy carpet of this station has 13 medium nitrophilous species 12 moderate nitrophilous, seven eurynitrophilous and four nitrophobic. Graphical interpretation is presented in Figure 2.

The phytocoenosis form the Dealul Negru station comprises 30 heliophytes species, followed by six meso-heliophytes species and other categories have a smaller number of species.

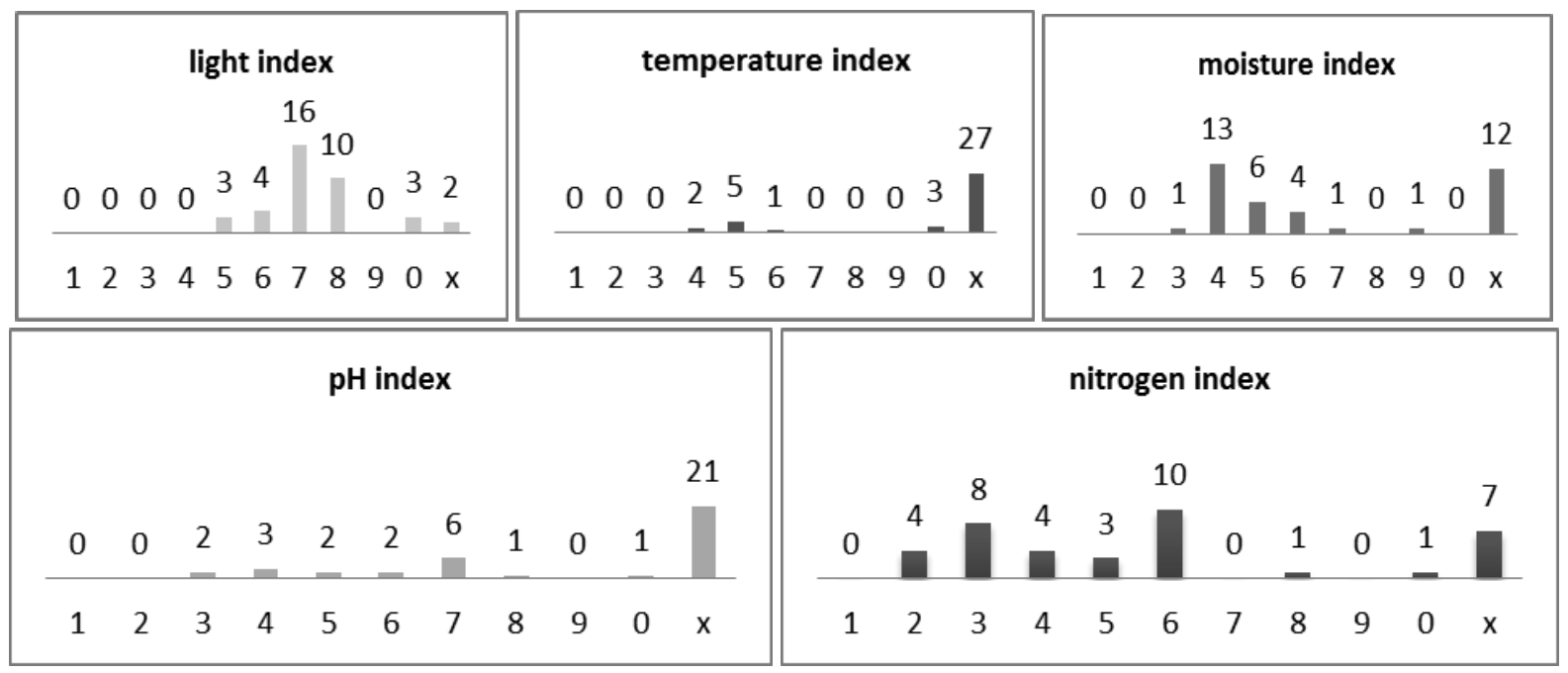

Fig. 2. Plant ecological requirements from Arin station

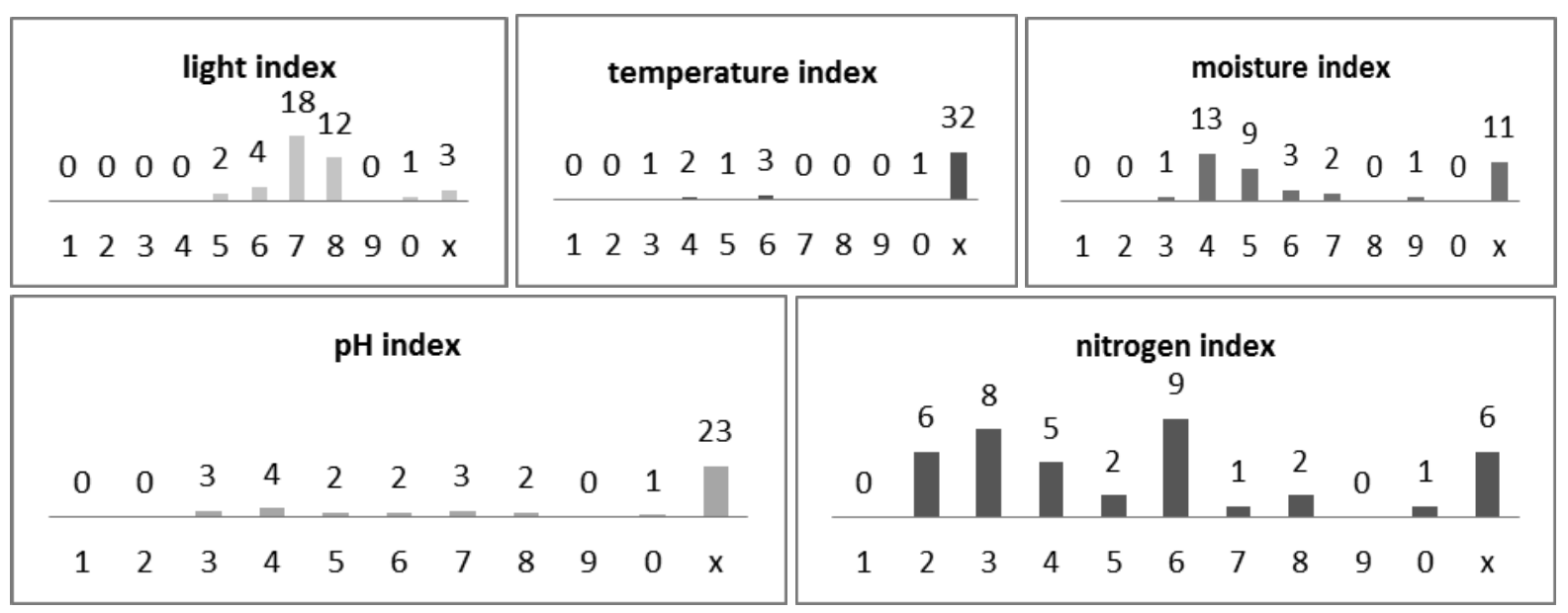

Fig. 3. Ecological requirements from Dealul Negru station. 
Regarding the requirement of plants to temperature, we found that 32 species are eurytherm, four species mesotherm and tree species microtherm.

In the grassy carpet of this type are present 23 species mesoxerophiles, 11 species euryecious and five species of mesophytes.

According to the requirement of plants to soil reaction, it is found that 23 species are euriacidophilous, seven moderate acidophilous, four lightlyacidophilous tree neutrophilous and two lightly alkaliphile.

As regards to the requirement on nitrogen supply, we found that 13 species are moderate nitrophilous, 12 nitrophobic, nine species are medium nitrophilous six eurynitrophilous and three nitrophilous. As shown in fig.3.

Plant communities from Fața Dâmbului comprise 35 heliophytes species, fallowed by nine meso-heliophyte species, two specii extremleyheliophyte and one euryecious species.

According to the temperature requirements 32 species are eurytherm, nine species are microtherm and two are mesotherm.

27 species are mesoxerophiles, 12 euryecious and nine mesophytes.

Regarding the soil reaction 29 species are euriacidophilous, 10 species are lightly- acidophilous and eight moderate-acidophilous.

On nitrogen requirements 21 species are medium nitrophilous, 13 are moderate nitrophilous, nine nitrophobic and six eurynitrophilous, presented in fig.4.

In the Arin station we determined the soil as beeing a Leptic Regosol - RG le (WRB-SR 1998).
Morphological caracters:

- Ao $0-10 \mathrm{~cm}$, very dark yellowish brown (10YR $3 / 2$ ), low glomerular structure, moderately developed, clayey, poorly consistent, weak adhesive, moist, moderately compact.

- A/C $10-30 \mathrm{~cm}$, yellowish brown (10YR 6/8), mean weak glomerular structure, low plasticity, low adhesion, clayey-sandy, gradual transition; moist, moderately compact.

- C: 30-55 cm, yellow (10YR 7/8) with weak stable structure, loam - sandy, moist, skeletal, compact.

The phisico-chemical are presented in table nr. 1 .

In the Dealul Negru station the soil that we encountered is Leptic Umbrisols - UM hu (WRBSR 1998).

Tab. 1. Analitical data for Leptic Regosols

\begin{tabular}{lccc}
\hline Horizonts & Ao & A/C & C \\
\hline Depths $(\mathrm{cm})$ & $0-10$ & $10-30$ & $30-55$ \\
\hline $\begin{array}{l}\text { Coarse sand }(2,0-0,2 \\
\text { mm)\% }\end{array}$ & 14.88 & 12.40 & 16.62 \\
\hline $\begin{array}{l}\text { Fine sand }(0,2- \\
0,0, \mathrm{~mm}) \%\end{array}$ & 38.53 & 41.90 & 39.13 \\
\hline Dust $(0,02-0,02 \mathrm{~mm}) \%$ & 8.0 & 9.45 & 8.55 \\
\hline Dust $(0,01-0,002 \mathrm{~mm}) \%$ & 17.15 & 16.95 & 15.25 \\
\hline Clay $(<0,002 \mathrm{~mm}) \%$ & 21.40 & 19.30 & 20.45 \\
\hline Texture & LL & $\mathrm{SF}$ & $\mathrm{LL}$ \\
\hline pH in $\left(\mathrm{H}_{2} \mathrm{O}\right)$ & 4.75 & 4.73 & 5.17 \\
\hline Total N $(\%)$ & 0.515 & 0.210 & 0.068 \\
\hline Mobile P $(\mathrm{ppm})$ & 9 & 5 & 5 \\
\hline Mobile K $(\mathrm{ppm})$ & 50 & 14 & 14 \\
\hline
\end{tabular}

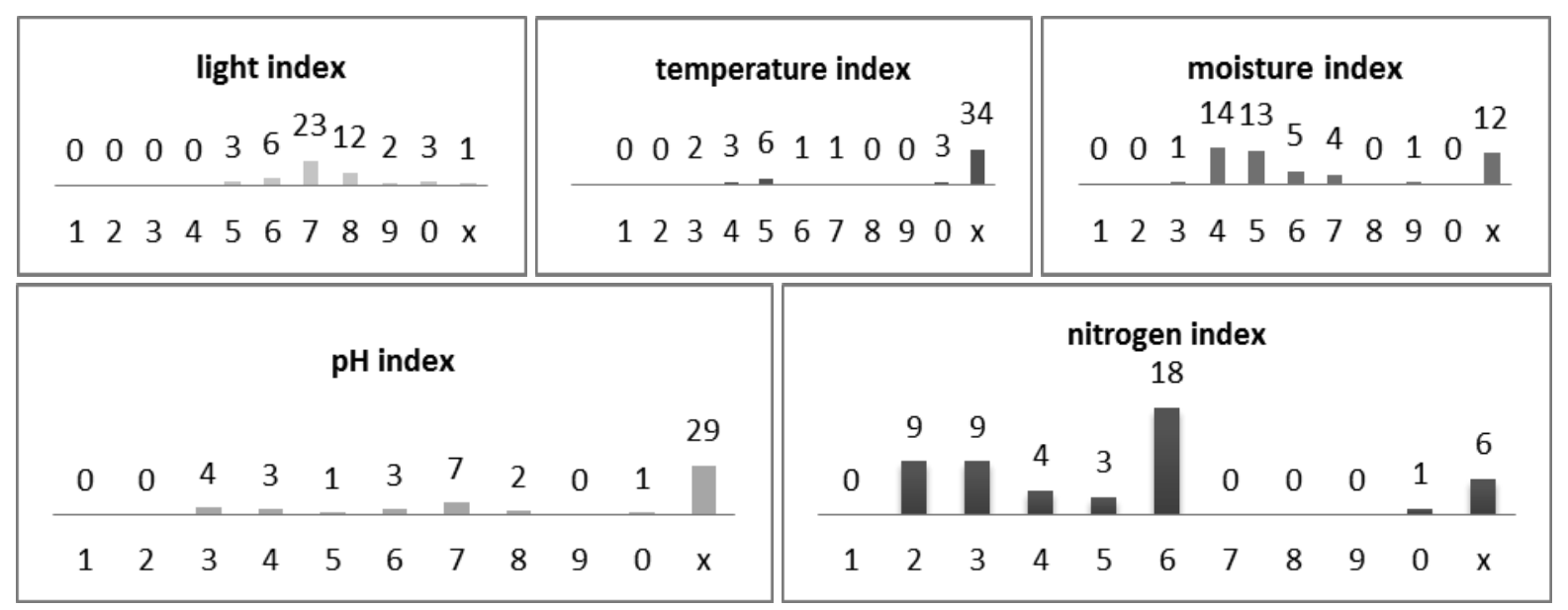

Fig. 4. Ecological requirements from Fața Dâmbului station. 
Morphological caracters:

- Au $0-25 \mathrm{~cm}$, very dark gray (10YR 3/1), glomerular structure, well developed, sandy loam, poorly consistent, poorly adhesive, moist, moderately compact.

- R: 25-40 cm, dark yellowish brown (10YR 4/4) with angular polyhedral structure, loamy, moist, compact.

The analitical data are presented in table nr. 2 .

We characterized the Fața Dâmbului soil as beeing a Skeleti-entic Podzols (PZ et-sk) (WRBSR 1998).

Morphological caracters:

- Aou 0 - $20 \mathrm{~cm}$ brown (10YR 4/3), glomerular structure well developed, sandy loam, poorly adhesive, moderately compact, moist.

- Bs: 20-45 cm, light yellowish brown (10YR 6/4) with angular polyhedral structure, fine sandy loam, compact, moist.

Analitical data are structured in table nr. 3.

\section{CONCLUSION}

The Agrostis capillaris - Festuca rubra grassland type has been encountered in two locations, with an exceptionaly high Fabaceae abundance. Due to the elevation factor the grassland type from the third hay meadow was a shift from the Festuca rubra type to Agrostis capillaris type or vice versa.

From the ecological point of view the plant species from the studied locations have a heliophyl tendency regarding the light requirements, a eurytherm caracter, a mesoxerophile preference towards the moisture index, the plants demand for the soil's reaction have a wide range of tolerance as for the nitrogen content in the soil they are mostley medium nitrophilous.

The soils that support these grasslands have in general a clay-sandy, clay texture, they are poorley supplied in potassium and phosphorus, but good, even excesive, supply of nitrogen in the first layer.

\section{ACKNOWLEDGEMENTS}

This paper was published under the frame of European Social Fund, Human Resources Development Operational Programme 2007-2013, project no. POSDRU/159/1.5/S/132765.

\section{REFERENCES}

1. BRAUN - BlanQuÉT J., 1932. Plant Sociology, the study of plant communities, Ed. Mc-Graw - Hill Book Company, Inc. New - York and London, 31-33
Tab. 2. Analitical data for Leptic Umbrisols

\begin{tabular}{lcc}
\hline Horizonts & $\mathrm{Au}$ & $\mathrm{R}$ \\
\hline Depths $(\mathrm{cm})$ & $0-25$ & $25-40$ \\
\hline Coarse sand $(2,0-0,2 \mathrm{~mm}) \%$ & 3.44 & 27.86 \\
\hline Fine sand $(0,2-0,0, \mathrm{~mm}) \%$ & 59.81 & 30.54 \\
\hline Dust $(0,02-0,02 \mathrm{~mm}) \%$ & 6.6 & 9.15 \\
\hline Dust $(0,01-0,002 \mathrm{~mm}) \%$ & 12.10 & 9.95 \\
\hline Clay $(<0,002 \mathrm{~mm}) \%$ & 18.05 & 22.50 \\
\hline Texture & $\mathrm{SM}$ & $\mathrm{LL}$ \\
\hline pH in $\left(\mathrm{H}_{2} \mathrm{O}\right)$ & 4.93 & 4.90 \\
\hline Total $\mathrm{N}(\%)$ & 0.375 & 0.132 \\
\hline P mobil $(\mathrm{ppm})$ & 10 & 8 \\
\hline K mobil $(\mathrm{ppm})$ & 38 & 20 \\
\hline
\end{tabular}

Tab. 3. Analitical data for Skeleti-entic Podzols

\begin{tabular}{lcc}
\hline Horizonts & Aou & Bs \\
\hline Depths $(\mathrm{cm})$ & $0-20$ & $20-45$ \\
\hline Coarse sand $(2,0-0,2 \mathrm{~mm}) \%$ & 36.26 & 36.14 \\
\hline Fine sand $(0,2-0,0, \mathrm{~mm}) \%$ & 31.04 & 28.76 \\
\hline Dust $(0,02-0,02 \mathrm{~mm}) \%$ & 7.50 & 9.80 \\
\hline Dust $(0,01-0,002 \mathrm{~mm}) \%$ & 9.80 & 10.35 \\
\hline Clay $(<0,002 \mathrm{~mm}) \%$ & 15.40 & 14.95 \\
\hline Texture & $\mathrm{SM}$ & $\mathrm{SF}$ \\
\hline pH in $\left(\mathrm{H}_{2} \mathrm{O}\right)$ & 4.59 & 5.01 \\
\hline Total N $(\%)$ & 0.597 & 0.139 \\
\hline Mobile P $(\mathrm{ppm})$ & 10 & 6 \\
\hline Mobile K $(\mathrm{ppm})$ & 58 & 14 \\
\hline
\end{tabular}

2. Coldea Gh., 1990: Muntii Rodnei. Studiu geobotanic, Edit. Academiei Române, Bucuresti.

3. Doniță N., Roman N., Coldea Gh., Ivan D., Dragu I., Munteanu I., 1985: Eine neue Vegetationskarrte von Rumanien, Rev. Roum. Biol. - Biol., Veget., 30 (1), p. 79-83

4. Ellenberg, H. 1988. Vegetation ecology of Central Europe, 4 edition. Cambridge: Cambridge University Press.

5. Kull K. and Zobel M. (1991) High species richness in an Estonian wooded meadow. Journal of Vegetation Science, 2, 715-718.

6. Pärtel M., Zobel M., Zobel K., and van der Maarel E. (1996) The species pool and its relation to species richness: evidence from Estonian plant communities. Oikos, 75, 111-117.

7. Veen, P., Jefferson, R., deSmidt, J. \& vanderStraaten, J., eds (2009) Grasslands in Europe of High Nature Value. Den Haag, The Netherlands: KKNV publishing. 